\section{Efficacy of amblyopia therapy initiated after 9 years of age}

KH Park, J-M Hwang and JK Ahn

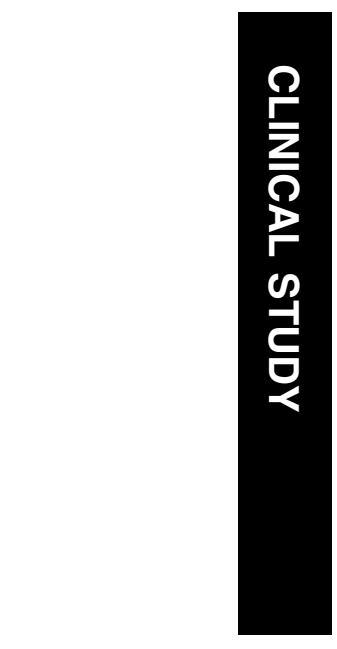

\begin{abstract}
Aims/purpose To evaluate the efficacy of occlusion therapy initiated after 9 years of age. Methods A total of 16 amblyopes of 9 years or older (range, 9.0-14.5 years; mean, 10.5 years) with a difference in visual acuity of over two lines between the eyes alter 4 weeks of first full-time spectacle wear were included. None of the children had undergone a previous ocular examination, had ever worn spectacles, received occlusion therapy, or had strabismus surgery. Initial worst visual acuity after 4 weeks of full-time spectacle wear was 20/100 in three patients, between 20/80 and 20/40 in 11 patients, and 20/30 in two patients. Full-time occlusion was performed in 14 patients and part-time occlusion in two patients.

Results The final visual acuity of 15 out of 16 patients $(94 \%)$ improved at least two lines. The final visual acuities ranged from $20 / 30$ to $20 / 20$ in 14 patients, 20/40 in one patient, and 20/50 in one remaining patient who began amblyopia therapy at $\mathbf{1 4 . 5}$ years of age, with the poorest compliance among the patients.

Conclusions Occlusion therapy for anisometropic and strabismic amblyopia can be successful even if initiated after the age of 9 years.

Eye (2004) 18, 571-574. doi:10.1038/

sj.eye. 6700671
\end{abstract}

Keywords: amblyopia; 9 years or older; occlusion; efficacy

\section{Introduction}

Amblyopia is a reduced corrected visual acuity without any evidence of organic eye disease. It is caused by an abnormal visual experience during a sensitive period of visual development in early childhood most commonly from either a strabismus, an anisometropia, or both. It has been treated by correcting the refractive errors followed by occlusion of the fellow eye. ${ }^{1}$ Many factors are related to the response to amblyopia therapy. These are the initial visual acuity of the amblyopia, $^{2-5}$ the age of the initial therapy, ${ }^{3-9}$ the type of amblyogenic stimulus (anisometropia, strabismus, or deprivation), ${ }^{2-5,9}$ the duration of amblyopia therapy, ${ }^{5}$ the method of amblyopia therapy, ${ }^{10,11}$ and the level of compliance. ${ }^{4-6,12}$ Among them, the single factor that was most clearly related to a successful outcome was the age at commencement of therapy. ${ }^{3}$ Regarding this age factor, there have been several reports with conflicting results. ${ }^{3-9}$ The purpose of this study was to evaluate the efficacy of amblyopia therapy initiated after 9 years of age, one of the oldest patient groups ever reported.

\section{Patients and methods}

The study was conducted from January 1995 to January 2000. All patients with amblyopia 9 years of age or older who were eligible and whose parents agreed to enrolment were included. All of the amblyopes with a difference in visual acuity of over two lines between the eyes after 4 weeks of full-time spectacle wear were included in this study. None of the children had undergone a previous ocular examination. Therefore, none had ever worn spectacles, received amblyopia therapy, or had strabismus surgery. Patients with previous histories of retinal or optic nerve disease, glaucoma, cataract, nystagmus, media opacities, ocular trauma, eye surgery, neurologic disease, cerebral palsy, and mental retardation were excluded. Informed consent was obtained from each patient.

A detailed ophthalmic examination, including an uncorrected visual acuity, bestcorrected visual acuity, slit-lamp examination, cycloplegic refraction, prism cover test, alternate prism cover and uncover test, examination of ductions and versions, pupillary examination, and fundus examination was
Department of Ophthalmology Seoul National University Bundang Hospital College of Medicine Seoul National University Sungnam, Korea

Correspondence: J-M Hwang Department of Ophthalmology Seoul National University Bundang Hospital 300 Kumi-dong, Bundang-ku Sungnam

Kyungki 463-707, Korea Tel: + 82317877372 Fax: + 82317874057

E-mail: hjm@snu.ac.kr

Received: 13 November 2002

Accepted: 21 February 2003

The authors have no proprietary interest in any of the materials used in this study

This study was supported by a grant from the Seoul National University Hospital Research Fund. 
undertaken. Visual acuity of the amblyopic and fellow eyes was measured by means of linear optotypes of Snellen type by a masked tester. The compliance was recorded at each clinic visit. For statistical analysis, visual acuities have been converted to logMAR equivalents.

Pre- and postocclusion visual acuities have been compared using paired $t$-tests. Analysis was also performed using the nonparametric method of Wilcoxon's signed rank test.

A total of 16 subjects consisting of eight boys and eight girls were enrolled in this study. All of them were 9 years or older (range, 9.0-14.5 years; mean, 10.5 years) at the commencement of amblyopia therapy for anisometropic (nos. 1-11; mean, 10.4 years; range, 9-14.5 years), strabismic (nos. 12, 13; mean, 11.5 years; range, 10.5-12.3 years), or anisometropic and strabismic (nos. 14-16; mean, 10.3 years; range, 9.2-11.2 years) amblyopia (Table 1). Anisometropic amblyopes were defined as amblyopia with spherical difference between the two eyes of +1.00 diopters (D) or more of hypermetropia or $-2.00 \mathrm{D}$ or more of myopia, and with no heterotropia in the alternate cover test. Strabismic amblyopes had exotropia of at least 15 prism diopter (PD) in the alternate cover test and a spherical difference between the two eyes of less than $0.75 \mathrm{D}$. Anisometropic and strabismic amblyopes had both exotropia of at least 10 PD in the alternate cover test and a spherical difference between the two eyes of $-2.00 \mathrm{D}$ or more of myopia. The average age at the commencement of amblyopia therapy for the 16 patients was 10.5 years (range, 9.0-14.5 years).

The initial therapy consisted of full optical spectacle correction for the amblyopic eye for 4 weeks and then followed by a full-time occlusion with adhesive patch in 14 patients and a part-time occlusion in two patients who showed a difference in visual acuity of over two lines between the eyes. A full spectacle correction was prescribed in all cases on the basis of a cycloplegic refraction with cyclopentolate hydrochloride $1 \%$ for 20-40 min. Following the initial period with occlusion along with spectacles, the changes in visual acuity were compared at 3-, 6-, 12-, and 24-month intervals. In patients with a low compliance, both the patient and their parents were asked to visit the clinic once a month and were given a great deal of encouragement and education as to the significance of amblyopia therapy. The patients and parents were asked to keep a diary of the occlusion time of each day. The parents were asked to bring a letter to school so that the patients could occlude their eyes even there. This therapy was continued until there was no further improvement in the visual acuity of the amblyopic eye for at least 3 months. In the 14 patients with full-time occlusion, 11 patients had part-time occlusion with a patch and three patients were given occlusive Min's glasses ${ }^{\mathbb{R}}$ (P \& M Inc., Daejon, Korea) ${ }^{13}$ so as to maintain the visual acuity after they were considered to have reached a plateau. Final visual acuity was defined as the visual acuity at the end of the study. After the maintenance therapy was discontinued, the visual acuity was retested 6-12 months later. If there was any decrease in visual acuity, the maintenance therapy was reinstituted.

The compliance was categorized as good if occlusion was performed $>70 \%$ of the time, fair if occlusion was performed for $30-70 \%$ of the time, and poor if occlusion was performed $<30 \%$ of the time.

Table 1 Clinical characteristics and outcome of amblyopia therapy in 16 patients

\begin{tabular}{|c|c|c|c|c|c|c|c|c|c|c|c|c|}
\hline \multirow[t]{2}{*}{ Patient/sex } & \multirow{2}{*}{$\begin{array}{c}\text { Initial age } \\
\text { (years) }\end{array}$} & \multicolumn{2}{|c|}{ Refraction } & \multirow{2}{*}{$\begin{array}{l}\text { Anisome- } \\
\text { tropia (D) }\end{array}$} & \multirow[t]{2}{*}{ Strabismus } & \multirow{2}{*}{$\begin{array}{c}\text { Final age } \\
\text { (years) }\end{array}$} & \multirow{2}{*}{$\begin{array}{c}\text { Occlusion } \\
\text { full/part-time } \\
\text { (months) }\end{array}$} & \multicolumn{2}{|c|}{ Initial VA } & \multicolumn{2}{|c|}{ Final VA } & \multirow{2}{*}{$\begin{array}{c}\text { Compliance } \\
(\%)\end{array}$} \\
\hline & & $\begin{array}{c}\text { Amblyopic } \\
\text { eye }\end{array}$ & $\begin{array}{c}\text { Fellow } \\
\text { eye }\end{array}$ & & & & & Snellen & logmar & Snellen & $\log M A R$ & \\
\hline $1 / F$ & 10.3 & -4.75 & -0.25 & -4.50 & Ortho & 11.1 & $1 / 4$ & $20 / 60$ & 0.5 & $20 / 20$ & 0 & - \\
\hline $2 / F$ & 9.0 & +3.75 & +0.75 & +3.00 & Ortho & 11.8 & $0 / 9$ & $20 / 40$ & 0.3 & $20 / 20$ & 0 & $>70$ \\
\hline $3 / F$ & 9.6 & -3.25 & -0.50 & -2.75 & Ortho & 11.0 & $8 / 0$ & $20 / 40$ & 0.3 & $20 / 25$ & 0.1 & $>70$ \\
\hline $4 / F$ & 9.0 & +5.75 & -1.75 & +7.50 & Ortho & 12.5 & $1 / 17$ & $20 / 40$ & 0.3 & $20 / 20$ & 0 & $>70$ \\
\hline $5 / \mathrm{M}$ & 9.0 & -4.75 & -1.75 & -3.00 & Ortho & 10.2 & $1 / 12^{\mathrm{a}}$ & $20 / 100$ & 0.7 & $20 / 30$ & 0.2 & $>70$ \\
\hline $6 / \mathrm{M}$ & 11.8 & +1.25 & -1.00 & +2.25 & Ortho & 13.6 & $1 / 7$ & $20 / 40$ & 0.3 & $20 / 20$ & 0 & $>70$ \\
\hline $7 / \mathrm{M}$ & 14.5 & +3.25 & +0.25 & +3.00 & Ortho & 15.5 & $0 / 10$ & $20 / 60$ & 0.5 & $20 / 50$ & 0.4 & $30-70$ \\
\hline $8 / \mathrm{M}$ & 9.0 & +2.75 & +1.75 & +1.00 & Ortho & 11.8 & $1 / 12^{\mathrm{a}}$ & $20 / 50$ & 0.4 & $20 / 20$ & 0 & - \\
\hline $9 / \mathrm{F}$ & 9.0 & +4.50 & +0.50 & +4.00 & Ortho & 11.3 & $1 / 26$ & $20 / 100$ & 0.7 & $20 / 20$ & 0 & $>70$ \\
\hline $10 / \mathrm{M}$ & 9.2 & -3.75 & -1.75 & -2.00 & Ortho & 10.2 & $5 / 2$ & $20 / 40$ & 0.3 & $20 / 20$ & 0 & $>70$ \\
\hline $11 / \mathrm{M}$ & 13.9 & +4.50 & +3.00 & +1.50 & Ortho & 14.9 & $1 / 4$ & $20 / 100$ & 0.7 & $20 / 40$ & 0.3 & - \\
\hline $12 / \mathrm{M}$ & 10.5 & -1.25 & -0.75 & -0.50 & $40 \times \mathrm{T}$ & 11.5 & $2 / 2$ & $20 / 40$ & 0.3 & $20 / 25$ & 0.1 & $>70$ \\
\hline $13 / F$ & 12.3 & -3.00 & -2.25 & -0.75 & $16 X(\mathrm{~T})$ & 10.9 & $3 / 12$ & $20 / 30$ & 0.2 & $20 / 20$ & 0 & $>70$ \\
\hline $14 / \mathrm{M}$ & 9.2 & -6.50 & -2.50 & -3.50 & $35 X \mathrm{~T}$ & 11.4 & $3 / 0$ & $20 / 40$ & 0.3 & $20 / 20$ & 0 & $>70$ \\
\hline $15 / \mathrm{F}$ & 11.2 & -4.00 & -2.00 & -2.00 & $10 X(\mathrm{~T})$ & 12.4 & $1 / 13$ & $20 / 30$ & 0.2 & $20 / 20$ & 0 & $>70$ \\
\hline $16 / F$ & 10.5 & -9.75 & -1.00 & -8.75 & $55 X \mathrm{~T}$ & 15.0 & $3 / 10 a$ & $20 / 40$ & 0.3 & $20 / 25$ & 0.1 & $>70$ \\
\hline
\end{tabular}

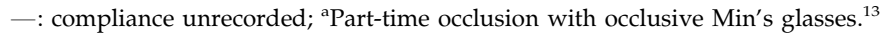




\section{Results}

Anisometropia was present in 11 patients (nos. 1-11), strabismus in two patients (nos. 12 and 13), and both anisometropia $\geq-2.00 \mathrm{D}$ and strabismus in three patients (nos. 14-16) (Table 1).

The initial worst visual acuity after 4 weeks of full-time spectacle wear was 20/100 in three patients, ranged from $20 / 80$ to $20 / 40$ in 11 patients, and 20/30 in two patients. The refractive errors of the amblyopic eye were myopic in seven patients, hyperopic in seven patients, and astigmatism in two patients. The average amount of anisometropia between the amblyopic eye and the fellow eye was $2.56 \mathrm{D}$. The type of strabismus was a constant exotropia of 35,40 , and 55 PD in three patients, and an intermittent exotropia of 10 and 16 PD in two patients (Table 1). Patient no. 16 showed a visual acuity of 20/40 1 month after he first came. The visual acuities of fellow eyes were 20/20 in 14 patients and 20/15 in the two remaining patients before patching, which did not show any significant improvement during the follow-up period.

The final visual acuity of 15 out of 16 patients (94\%) at the end of the study improved by at least two lines. The final visual acuities ranged from $20 / 20$ to $20 / 30$ for 14 patients, 20/40 in one patient (no. 11), and 20/50 in the remaining patient (no. 7). Patient no. 11 underwent occlusion therapy from age 13.9 to 14.9 years and the visual acuity had improved from 20/100 to 20/40. Patient no. 7 underwent occlusion therapy from age 14.5 to 15.5 years and showed just a one-line improvement, with the poorest compliance among the patients (Table 1).

Paired $t$-tests and Wilcoxon's signed rank test showed a statistically significant difference between mean preand postocclusion visual acuities converted to logMAR equivalents $(0.39375$ vs $0.075, P<0.001)$.

The duration of therapy averaged 10 months (range, 3-27 months). The compliance was $>70 \%$ in 12 out of the 16 patients $(75 \%)$. Improvement in the visual acuity occurred mostly in the initial 3-6 months (Figures 1 and 2). Occlusion-induced amblyopia did not occur in any patient. The average follow-up period was 24 months (range, 12-63 months).

There was no patient who developed diplopia after patching. Regarding the binocular state of strabismus before and after patching, two patients (nos. 13 and 15) with intermittent exotropia showed less than 6 PD of exophoria after improvement of visual acuity with patching. Among three patients with constant exotropia, two showed less than 10 PD of exophoria or intermittent exotropia and one remaining patient (no. 14) underwent bilateral rectus recession after improvement of visual acuity with patching. Titmus stereo test in patients 12-16 showed 200-60s of arc of stereoacuities, which did not

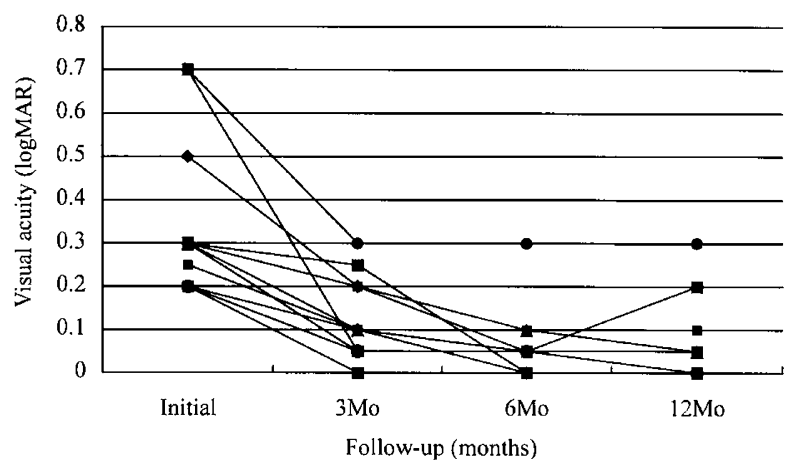

Figure $1 \log$ MAR visual acuity in anisometropic amblyopia. Improvement in the visual acuity occurred mostly in the initial 3-6 months.

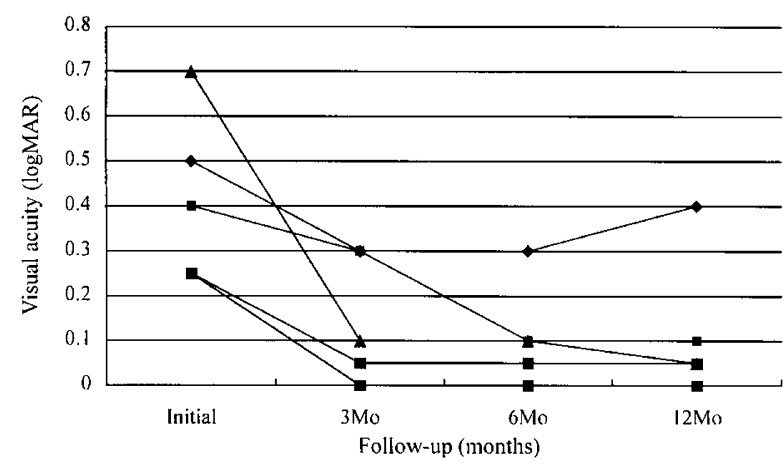

Figure $2 \log$ MAR visual acuity in strabismic amblyopia, and in anisometropic and strabismic amblyopia. Improvement in the visual acuity occurred mostly in the initial 3-6 months.

show any significant improvement over the two-level difference before and alter improvement of visual acuity.

\section{Discussion}

There is general agreement that amblyopia must be treated at an early age and that treatment is more prolonged and less beneficial in older children. ${ }^{3-9}$ However, the age beyond which treatment is ineffective is still controversial. Oliver et $a l^{5}$ also found that children older than 8 years who complied with the treatment showed a marked improvement in their visual acuity, almost as good as that in younger children. MintzHittner and Fernandez ${ }^{6}$ reported significant improvements in the visual acuity of 36 compliant children between the ages of 7.0 and 10.3 years undergoing an occlusion or penalization therapy. ${ }^{6}$ Hedgpeth and Sullivan ${ }^{7}$ also reported that an anisometropic amblyopia could be treated successfully at least until the age of 12 years. In contrast, Rutstein and $\mathrm{Fuhr}^{8}$ reported that a visual acuity of $20 / 40$ or better could be obtained in only $27 \%$ of patients older than 8 years. Epelbaum et $a l^{9}$ also reported that the efficiency of strabismic amblyopia treatment decreased as a function 
of age and was nil by the time the patient had reached 12 years of age, and only children with an anisometropic amblyopia responded to therapy at the later ages. It was reported that the greater the compliance, the better the result. $5,6,12$ The reported high failure rates in older children might be attributed to the lack of compliance rather than to age-related factors. Our study strongly reaffirms that given compliance, occlusion therapy for either anisometropic or strabismic amblyopia can be successful even if initiated after the age of 9 years.

In our amblyopes of 9.0-14.5 years of age at commencement of the occlusion, 14 out of 16 patients $(88 \%)$ had improved their visual acuity by up to $20 / 30$. If the one patient of 14.5 years of age at initiation of occlusion is excluded, all of the patients 9.0-12.3 years of age at the initiation of occlusion improved their visual acuity better than $20 / 40$. The recorded compliance was good, with more than $70 \%$ of the occlusion in every recorded patient except the 14.5-year-old patient. This result means that amblyopia therapy for anisometropic and strabismic amblyopia can be successful even if initiated after the age of 9 years as long as there is good compliance.

There has been some debate as to how long the critical period of visual development actually lasts. The critical period for development does not necessarily follow the same time course as the plastic period during which the visual system is still amenable to successful treatment. In humans, even adults with amblyopia demonstrated residual plasticity in the visual system. ${ }^{414-18}$ Our results also suggest that amblyopia can be treated successfully beyond the age that is usually considered to be the critical period for the development of amblyopia. Therefore, the plastic period for treating amblyopia may extend beyond the critical development period substantially, and the age of the patient should not be a limiting factor for determining whether or not to institute therapy.

In this study, most of the improvement occurred during the first 3 months of treatment regardless of the type of amblyopia (Figures 1 and 2). The same result could be found in other studies for amblyopes in other age groups. ${ }^{5,19,20}$ Thus given compliance, the response of occlusion therapy for the initial 3 months could be invaluable for predicting the prognosis of the amblyopia.

In conclusion, a therapeutic trial is advisable even in older children, provided the patient is compliant. The period of visual acuity recovery for amblyopia should be extended beyond the conventional view of 7 years of age as the upper limit for treatment.

\section{References}

1 von Noorden GK, Campos EC. Examination of the patientIV amblyopia. In: von Noorden GK, Campos EC (eds).
Binocular Vision and Ocular Motility, 6th ed. Mosby: Missouri, 2002, pp 246-287.

2 Levartovsky S, Oliver M, Gottesman N, Shimshoni M. Factors affecting long term results of successfully treated amblyopia: initial visual acuity and type of amblyopia. Br J Ophthalmol 1995; 79: 225-228.

3 Flynn JT, Schiffman J, Feuer W, Corona A. The therapy of amblyopia: an analysis of the results of amblyopia therapy utilizing the pooled data of published studies. Trans Am Ophthalmol Soc 1998; 96: 431-453.

4 Woodruff G, Hiscox F, Thompson JR, Smith LK. Factors affecting the outcome of children treated for amblyopia. Eye 1994; 8 (Part 6): 627-631.

5 Oliver M, Neumann R, Chaimovitch Y, Gottesman N, Shimshoni M. Compliance and results of treatment for amblyopia in children more than 8 years old. Am J Ophthalmol 1986; 102: 340-345.

6 Mintz-Hittner HA, Fernandez KM. Successful amblyopia therapy initiated after age 7 years: compliance cures. Arch Ophthalmol 2000; 118: 1535-1541.

7 Hedgpeth EM, Sullivan M. Anisometropic amblyopia and its treatment. South Med J 1977; 70: 1059-1060.

8 Rutstein RP, Fuhr PS. Efficacy and stability of amblyopia therapy. Optom Vis Sci 1992; 69: 47-54.

9 Epelbaum M, Milleret C, Buisseret P, Dufier JL. The sensitive period for strabismic amblyopia in humans. Ophthalmology 1993; 100: 323-327.

10 Simons K, Stein L, Sener EC, Vitale S, Guyton DL. Full-time atropine, intermittent atropine, and optical penalization and binocular outcome in treatment of strabismic amblyopia. Ophthalmology 1997; 104: 2143-2155.

11 The Pediatric Eye Disease Investigator Group. A randomized trial of atropine vs patching for treatment of moderate amblyopia in children. Arch Ophthalmol 2002; 120: 268-278.

12 Smith LK, Thompson JR, Woodruff G, Hiscox F. Factors affecting treatment compliance in amblyopia. J Pediatr Ophthalmol Strabismus 1995; 32: 98-101.

13 Min BM, Kim SY, Ko KH, Lee SB. A comparison of Min's glasses and conventional occlusion therapy in the treatment of amblyopic children: a prospective study. Korean $J$ Ophthalmol 2000; 14: 32-37.

14 Levi DM, Polat U, Hu YS. Improvement in Vernier acuity in adults with amblyopia: practice makes better. Invest Ophthalmol Vis Sci 1997; 38: 1493-1510.

15 El Mallah MK, Chakravarthy U, Hart PM. Amblyopia: is visual loss permanent? Br J Ophthalmol 2000; 84: 952-956.

16 Rabin J. Visual improvement in amblyopia after visual loss in the dominant eye. Am J Optom Physiol Optics 1984; 61: 334-337.

17 Vereecken EP, Brabant P. Prognosis for vision in amblyopia after the loss of the good eye. Arch Ophthalmol 1984; 102: 220-224.

18 Hamed LM, Glaser JS, Schatz NJ. Improvement of vision in the amblyopic eye following visual loss in the contralateral normal eye: a report of three cases. Binoc Vis 1991; 6: 97-100.

19 Lithander J, Sjostrand J. Anisometropic and strabismic amblyopia in the age group 2 years and above: a prospective study of the results of treatment. Br J Ophthalmol 1991; 75: 111-116.

20 Nucci P, Alfarano R, Piantanida A, Brancato R. Compliance in antiamblyopia occlusion therapy. Acta Ophthalmol (Copenh) 1992; 70: 128-131. 